Article

\title{
Multiblock Copolymers of Styrene and Butyl Acrylate via Polytrithiocarbonate-Mediated RAFT Polymerization
}

\section{Bastian Ebeling and Philipp Vana *}

Institut für Physikalische Chemie, Georg-August-Universität Göttingen, Tammannstraße 6, D-37077

Göttingen, Germany

* Author to whom correspondence should be addressed; E-Mail: pvana@ uni-goettingen.de;

Tel.: +49-551-39-12753; Fax: +49-551-39-3144.

Received: 18 February 2011; in revised form: 18 March 2011 / Accepted: 28 March 2011 /

Published: 31 March 2011

\begin{abstract}
When linear polytrithiocarbonates as Reversible Addition-Fragmentation chain Transfer (RAFT) agents are employed in a radical polymerization, the resulting macromolecules consist of several homogeneous polymer blocks, interconnected by the functional groups of the respective RAFT agent. Via a second polymerization with another monomer, multiblock copolymers-polymers with alternating segments of both monomers - can be prepared. This strategy was examined mechanistically in detail based on subsequent RAFT polymerizations of styrene and butyl acrylate. Size-exclusion chromatography (SEC) of these polymers showed that the examined method yields low-disperse products. In some cases, resolved peaks for molecules with different numbers of blocks (polymer chains separated by the trithiocarbonate groups) could be observed. Cleavage of the polymers at the trithiocarbonate groups and SEC analysis of the products showed that the blocks in the middle of the polymers are longer than those at the ends and that the number of blocks corresponds to the number of functional groups in the initial RAFT agent. Furthermore, the produced multiblock copolymers were analyzed via differential scanning calorimetry (DSC). This work underlines that the examined methodology is very well suited for the synthesis of well-defined multiblock copolymers.
\end{abstract}

Keywords: multiblock copolymers/segmented block copolymers; Reversible Addition-Fragmentation chain Transfer (RAFT); polytrithiocarbonates; molecular weight distribution/molar mass distribution 


\section{Introduction}

Multiblock copolymers (or segmented block copolymers) consist of alternating homogeneous segments of two different monomers which are attached covalently to each other. If these monomers are chemically distinct, they differ significantly from the respective random copolymers or blends of the homopolymers. Arguably the most noted property of multiblock copolymers is their ability to self-assemble into ordered microstructures when the segments are sufficiently long [1,2]. The microphase separation of multiblock copolymers with long alternating hard and soft segments gives rise to their unique material properties as thermoplastic elastomers $[3,4]$. Other industrial uses of the bulk polymers include the utilization as compatibilizers $[5,6]$ for blends of otherwise immiscible homopolymers and as pressure-sensitive adhesives [7,8]. Certain multiblock copolymers can form responsive polymeric hydrogels. These are smart materials which have potential applications in drug delivery, tissue engineering, and as sensors [9-11]. The motif of multiblock copolymers can also be found in nature, where long flexible segments alternate with those which can form hydrogen bonds. The semi-crystalline structures that are formed in these cases are responsible for the extraordinarily good material properties of several biopolymers [12]. It seems promising to mimic this motif and prepare multiblock copolymers that comprise hydrogen bonding segments [13]. It has already been shown by us and others that these polymers have distinct mechanical properties compared to the corresponding polymers without hydrogen bonding segments $[14,15]$.

Based on these applications, several methodological criteria can be derived which should be met by a suitable synthesis strategy: The strategy should be (i) easy to implement, i.e., should not involve high costs or require a lot of time and no special equipment should be necessary. It should be (ii) capable of producing molecules with long segments which (iii) ideally all have the same length. It should enable the possibility (iv) to produce polymers with a high number of alternating segments and, moreover, (v) to control this number. Furthermore, (vi) the distribution of the segments among the synthesized polymers should be as narrow as possible. And after all, (vii) the method should be universally applicable, i.e., it should be deployable for a high number of different monomers and have a high tolerance towards functional groups, solvents and impurities. Up to recent times, no synthesis strategy has been found that meets all of these seven criteria in a reasonably acceptable manner.

The conventional method for the synthesis of multiblock copolymers is the preparation of end group functionalized prepolymers that are then coupled together by means of a coupling reaction. This method is relatively easy to implement (although it still requires at least three independent reactions) and is very versatile. It was already carried out with a variety of different monomers. As long as the used prepolymers are equal in their lengths, the same will hold true for the segments in the produced multiblock copolymers. On the other hand, this strategy entails some fundamental limitations: Because of the low concentration of reactive chain ends, no molecules with long segments (typically $<5,000 \mathrm{~g} \mathrm{~mol}^{-1}$ ) or with high numbers of alternating segments can be produced. Moreover, this number can hardly be controlled. Furthermore, the segment distribution among the molecules (Schultz-Flory distribution with ideal kinetics) is rather broad. However, the coupling approach is clearly the most widely used strategy, both in industry and academia.

In principle, segmented copolymers can also be prepared via stepwise alternating addition of two different monomers to a living polymerization, traditionally an anionic polymerization [16]. In this way, multiblock copolymers with an easily controllable number of alternating segments with arbitrarily 
specifiable lengths can be produced whereby ideally all molecules possess the same number of alternating segments. These advantages, however, are counterbalanced by an extremely high experimental effort when high numbers of segments are targeted because for each segment a separate reaction is necessary. Until today, to our knowledge, the highest number of segments that was reached by this method is 8 [17]. Additionally, the applicability of this strategy is limited as only certain pairs of monomers can be used.

With the advent of controlled radical polymerization (according to IUPAC: reversible-deactivation radical polymerization, RDRP), the principle of living polymerization has also been introduced to radical polymerization. Reversible Addition-Fragmentation chain Transfer (RAFT) polymerization [18,19] is arguably the most versatile among these techniques with respect to temperature [20], solvent [21], and monomer choice [22], and can be used to synthesize a wide variety of polymeric structures [23]. It proceeds via a degenerative chain transfer mechanism, which induces equilibrium between propagating macroradicals and dormant polymeric RAFT agents carrying dithio moieties [24] and has already been successfully employed to produce multiblock copolymers by stepwise addition of monomers to the polymerization $[25,26]$.

Trithiocarbonates (TTC) are unique RAFT agents in the sense that they are inherently bifunctional so that a polymer chain is inserted on both sides of the functional group when it is connected to good leaving groups. When a RAFT agent of trithiocarbonate type is employed in a radical polymerization, only two polymerization steps are necessary to prepare polymers with three alternating segments [27] and with every subsequent polymerization step the number of alternating segments of the polymers is increased by two. The number of alternating segments which is produced within two polymerizations can be further increased by utilizing a RAFT agent that contains multiple trithiocarbonate groups along its main chain. This strategy was pioneered by You et al. [28] who used it to synthesize polymers with alternating segments of polystyrene and poly(methyl acrylate) in UV-initiated RAFT polymerizations. The whole route is illustrated in Scheme 1. In the first polymerization, homopolymer blocks grow between the functional groups and on the ends of the polymer chains [29,30]. By a subsequent radical polymerization with another monomer, multiblock copolymers can be produced. (The term "block" is used ambiguously in the literature to describe both polymeric chains between particular functional groups and parts of homogeneous monomeric composition along a polymer chain. To avoid misunderstanding, the latter will be denoted "segment" in this article, while "block" will only be referred to the parts of the polymers which are separated by the trithiocarbonate groups. With this definition, the number of blocks in the polymers is not altered by the second polymerization step. Accordingly, "multiblock (homo)polymer" describes a (homo)polymer with several trithiocarbonate groups along the main chain. "Multiblock copolymer", however, is still used synonymously with "segmented copolymer", as defined before.) When the RAFT agent possesses $g$ functional groups, ideally polymers with $2 g+1$ alternating segments are prepared. In addition, RAFT polymerization with polytrithiocarbonates has already been used to prepare segmented copolymers composed of poly $(N, N$-dimethylacrylamide) (DMA) and poly( $N$-isopropylacrylamide) (NIPAM) [31], of polystyrene and poly(4-tert-butylstyrene) [32] and of a random DMA-NIPAM copolymer and poly(4-vinylpyridine) [33]. It has been shown that this strategy can also be carried out preparing the polytrithiocarbonates in situ by employing cyclic trithiocarbonates in the first polymerization $[34,35]$. It goes without saying that in principle also RAFT agents with other chemical groups (e.g., difunctional dithiocarbamates [36]) can be utilized. 
Scheme 1. General strategy for the synthesis of multiblock copolymers using polytrithiocarbonate RAFT agents.

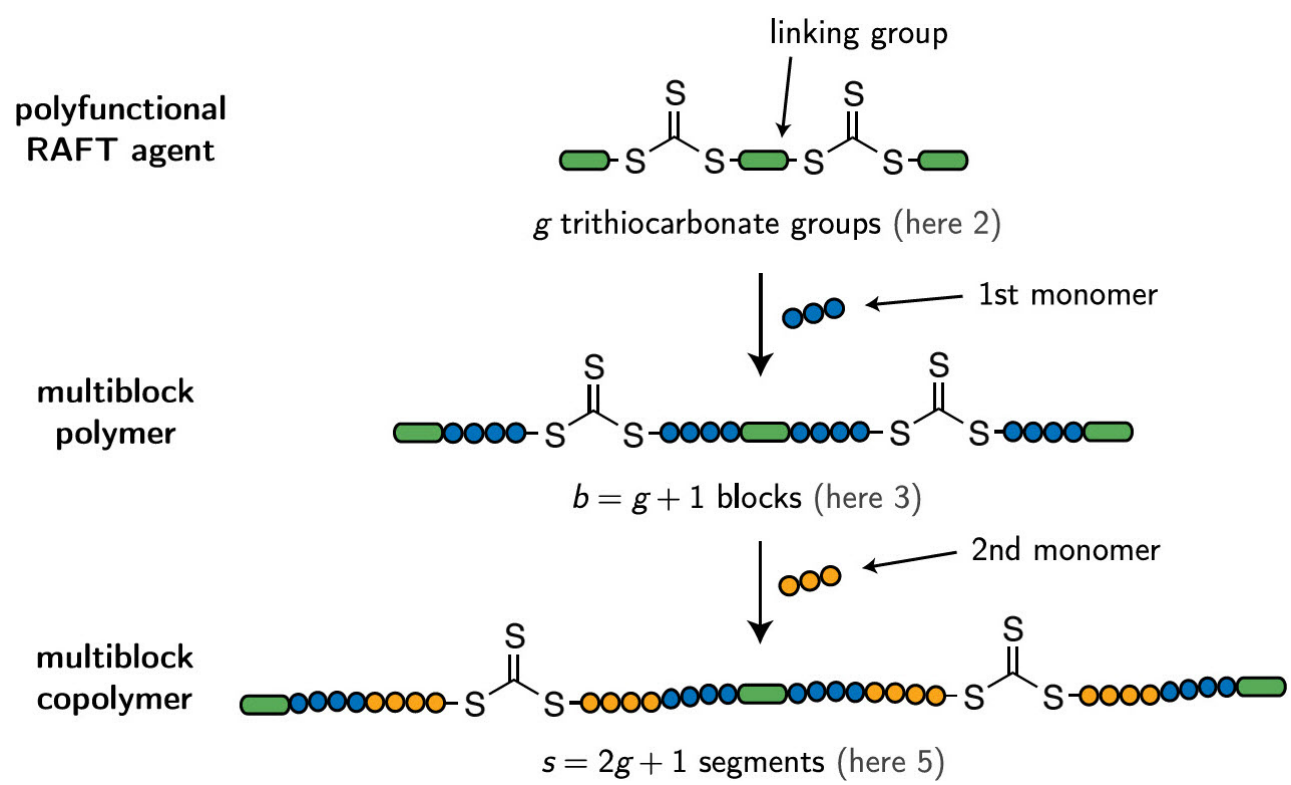

This approach appears to be very promising for the synthesis of multiblock copolymers. The here presented study was conducted to gain further insight into this method in order to be able to assess to what extent the examined strategy meets the above listed methodological criteria from an experimental point of view. The ideal segment distribution among the synthesized copolymers was already treated in another article, where we showed that multiblock copolymers prepared with the examined RAFT strategy ideally have a higher homogeneity than those from coupling of functionalized prepolymers [37]. In the present study, we examined the synthesis of segmented copolymers based on polystyrene and poly $(n$-butyl acrylate) (pBA) with a polyfunctional RAFT agent of trithiocarbonate type. The prepared polymers were probed by size-exclusion chromatography (SEC) and differential scanning calorimetry (DSC). By cleavage of the products at the trithiocarbonate groups and analysis of the products additional mechanistic information could be obtained.

\section{Experimental}

\subsection{Materials}

The anion exchange resin AMBERSEP ${ }^{\circledR} 900$ OH (FLUKA, 20-50 mesh) was dried for several days under high vacuum. By titration of an aqueous suspension with hydrochloric acid, its capacity was determined to be $3.5 \mathrm{mmol} \mathrm{g}^{-1}$. To remove the inhibitor, styrene and butyl acrylate (ALDRICH) were passed through a basic alumina (ALDRICH, Brockmann I, 150 mesh, $58 \AA$ ) column. 2,2'-Azobis(isobutyronitrile) (AIBN, AKZONOBEL) was recrystallized from methanol and dried under high vacuum before use. Tetrahydrofuran (THF) used as the eluent in SEC (Carl Roth, stabilized with 2,6-di-tert-butyl-4-methylphenol) was used as received. Unless otherwise specified, all other chemicals were purchased from ALDRICH and used without further purification. 


\subsection{Instrumentation}

Molecular weight distributions were measured by means of SEC using a system composed of a JASCO AS-2055PLUS autosampler, a WATERS 515 pump, three PSS SDV columns $(8 \times 300 \mathrm{~mm}$, nominal particle size: $5 \mu \mathrm{m}$, pore sizes: $10^{5}, 10^{3}$ and $10^{2} \AA$ ), a WATERS 2410 refractive index detector and a VISCOTEK VE 3210 ultraviolet (UV) detector (set to a wavelength of $310 \mathrm{~nm}$ ). THF at $35^{\circ} \mathrm{C}$ was used as the eluent at a flow rate of $1.0 \mathrm{~mL} \mathrm{~min}^{-1}$. The SEC set-up was calibrated against PSS polystyrene standards of very low dispersity. The molecular weight distributions were adjusted according to the principle of universal calibration using Mark-Houwink parameters for linear pBA $\left(K=1.22 \times 10^{-4} \mathrm{dL} \mathrm{g}^{-1}\right.$, $a=0.700)$ [38].

Nuclear magnetic resonance (NMR) spectra were recorded at room temperature on a VARIAN UNITY $300\left({ }^{1} \mathrm{H},{ }^{13} \mathrm{C}\right)$ or a VARIAN INOVA $500\left({ }^{1} \mathrm{H}\right)$ spectrometer, using deuterated chloroform as solvent and internal standard.

Differential scanning calorimetry was carried out on a METTLER TOLEDO DSC 820 apparatus which was operated with the STARe 9.01 software. Samples of 10-20 mg were heated under nitrogen atmosphere (flow rate $14 \mathrm{~mL} \mathrm{~min}^{-1}$ ) from $-52{ }^{\circ} \mathrm{C}$ to $170{ }^{\circ} \mathrm{C}$ and cooled back to $-52^{\circ} \mathrm{C}$. To obtain the thermograms the samples were heated again to $170{ }^{\circ} \mathrm{C}$. The heating and cooling rates were $10^{\circ} \mathrm{C} \mathrm{min}-1$. The glass transition temperature was taken as the onset temperature of the steps in the thermograms.

\subsection{Synthesis of Polytrithiocarbonate $\boldsymbol{A}$}

In the synthesis of polytrithiocarbonate $\mathbf{A}$ with the lowest degree of polymerization (see Table 1), cesium carbonate was employed as the base to produce trithiocarbonate ions [39]. Carbon disulfide $(409 \mu \mathrm{L}, 6.79 \mathrm{mmol})$ was added to a solution of cesium carbonate $(2.21 \mathrm{~g}, 6.79 \mathrm{mmol})$ in $5 \mathrm{~mL}$ acetonitrile at room temperature. The color of the suspension changed to red. After $10 \mathrm{~min}$ of stirring, dimethyl 2,6-dibromoheptanedioate $(739 \mu \mathrm{L}, 3.40 \mathrm{mmol})$ was added and the color changed to yellow immediately. After another $21 \mathrm{~h}$ of stirring, dimethyl 2,6-dibromoheptanedioate $(100 \mu \mathrm{L}, 460 \mu \mathrm{mol})$ was added again. The suspension was stirred for $45 \mathrm{~min}$ and poured into water $(100 \mu \mathrm{L})$. A yellow oil precipitated which was isolated and washed with water $(2 \times 100 \mathrm{~mL})$ and methanol $(2 \times 100 \mathrm{~mL})$. The product $(665 \mathrm{mg}$, $67 \%$ ) was dried under vacuum for $2 \mathrm{~d}$. See synthesis of $\mathbf{B}-\mathbf{E}$ for NMR spectroscopic data.

\subsection{Synthesis of Polytrithiocarbonates $\boldsymbol{B}-\boldsymbol{E}$}

In the synthesis of the polytrithiocarbonates $\mathbf{B}-\mathbf{E}$ with higher degrees of polymerization (see Figure 2 and Table 1), the trithiocarbonate ions were generated at the surface of an anion exchange resin [40,41]. A typical procedure is reported here. Dry AMBERSEP ${ }^{\circledR} 900 \mathrm{OH}\left(13 \mathrm{~g}, 46 \mathrm{mmol} \mathrm{OH}^{-}\right)$was suspended in carbon disulfide $(65 \mathrm{~mL})$. The surface of the resin beads turned dark red immediately. Dimethyl 2,6-dibromoheptanedioate $(5.00 \mathrm{~mL}, 23.0 \mathrm{mmol})$ was added. The suspension was heated to boiling and was stirred for $65 \mathrm{~h}$ under reflux. The color of the resin beads and the surrounding solution turned dark yellow over time. The reaction mixture was cooled to room temperature, poured in a fritted funnel and rinsed subsequently first with carbon disulfide $(300 \mathrm{~mL})$ and then with THF $(300 \mathrm{~mL})$. Both obtained fractions were concentrated under vacuum, washed with water $(3 \times 200 \mathrm{~mL})$ and methanol $(3 \times 150 \mathrm{~mL})$ and dried under high vacuum and were thus obtained as yellowish-orange oils, whereas the fraction 
obtained from rinsing with carbon disulfide $(1.55 \mathrm{~g}, 23 \%)$ was less viscous and paler in color than the THF fraction (771 mg, 11\%).

${ }^{1} \mathbf{H}-\mathrm{NMR}\left(300 \mathrm{MHz}, \mathbf{C D C l}_{3}\right): \delta=1.40-1.70\left(\mathrm{~m}, \mathrm{CH}_{2}-\mathrm{CH}_{2}-\mathrm{CH}_{2}\right), 1.85-2.14\left(\mathrm{~m}, \mathrm{CH}_{2}-\mathrm{CH}_{2}-\mathrm{CH}_{2}\right)$, 3.75 (s, $\left.\mathrm{COOCH}_{3}\right), 4.14-4.24(\mathrm{~m}, \mathrm{CH}-\mathrm{Br}), 4.59-4.79(\mathrm{~m}, \mathrm{CH}-\mathrm{S})$ ppm. ${ }^{13} \mathrm{C}-\mathrm{NMR}(\mathbf{7 5 . 5 8} \mathbf{~ M H z}$, $\left.\mathbf{C D C l}_{3}\right): \delta=22.1\left(\mathrm{CH}_{2}-\mathrm{CH}_{2}-\mathrm{CH}_{2}\right), 30.5\left(\mathrm{CH}-\mathrm{CS}_{3}\right), 44.8(\mathrm{CH}-\mathrm{Br}), 53.0\left(\mathrm{COO}-\mathrm{CH}_{3}, \mathrm{CH}-\mathrm{SCS}_{2}\right)$, $170.4\left(\mathrm{COO}-\mathrm{CH}_{3}\right), 219.2(\mathrm{~S}-\mathrm{CS}-\mathrm{S}) \mathrm{ppm}$.

\subsection{Polymerizations $\mathbf{1}-\mathbf{9}$ and $\mathbf{I}-\boldsymbol{V I}$}

Polymerizations 1-6 of styrene and 7-9 of BA with the prepared polytrithiocarbonates as RAFT agents were carried out in bulk at $60{ }^{\circ} \mathrm{C}$ and ambient pressure using AIBN as initiator. Polymerizations I-VI of butyl acrylate with the prepared multiblock styrene-homopolymers were carried out in solution of toluene under the same conditions. See Tables $2-4$ for the individual conditions. The indicated concentrations of the RAFT agents are referred to the molar masses which were measured by means of SEC and to the number of molecules, rather than the number of trithiocarbonate groups.

All polymerization mixtures were thoroughly degassed via three freeze-pump-thaw cycles and then evenly portioned into three to five capped glass vials in an argon-filled glove-box which were then inserted into a heating block. The reactions were stopped by cooling the vials in ice water after distinct time periods and residual monomer and solvent (I-VI) were removed by evaporation. Monomer to polymer conversion was determined by gravimetry.

\subsection{Cleavage of the Polymers}

Aminolysis without further treatment

The multiblock polymer $(10 \mathrm{mg})$ was dissolved in THF $(3 \mathrm{~mL})$ and $n$-butyl amine $(1.0 \mathrm{~mL}, 10 \mathrm{mmol})$ was added. The mixture was shaken for $1 \mathrm{~d}$ at room temperature. After drying, colorless polymers were obtained.

Aminolysis with Michael addition sealing

A typical procedure is described [42]. The multiblock polymer $(10 \mathrm{mg})$ and a very small amount of tris(2-carboxyethyl) phosphine hydrochloride (TCEP. $\mathrm{HCl}$ ) were dissolved in THF $(6 \mathrm{~mL})$ and $n$-butyl amine $(0.20 \mathrm{~mL}, 2.0 \mathrm{mmol})$ was added. The solution was shaken for $36 \mathrm{~h}$ and $\mathrm{BA}(0.2 \mathrm{~mL}, 1.4 \mathrm{mmol})$ was added. After another $24 \mathrm{~h}$, the colorless polymers were precipitated by addition of methanol and dried.

\section{Results}

\subsection{Preparation of the Polyfunctional RAFT Agents}

The general structure of the polyfunctional RAFT agents that were used in this study is depicted in Figure 1. It is comparable to the one used by You et al. but contains one methylene group less per unit. These polytrithiocarbonates were generally prepared by the polycondensation reaction of dimethyl 2,6-dibromoheptanedioate and trithiocarbonate anions. Two different strategies were followed to produce 
the trithiocarbonate anions via the reaction of carbon disulfide with a base: The first one (procedure 1) involves the production of the trithiocarbonate anions with cesium carbonate as the base [39]. However, it could only be successfully employed to prepare polyfunctional RAFT agents of very low degree of polymerization at room temperature. At elevated temperatures or longer reaction times, a side-product was formed, presumably because of the reaction of the dibromide's ester groups [43]. The second strategy (procedure 2) was based on the formation of the trithiocarbonate anions on the surface of an anion exchange resin. You et al. published a synthesis for polytrithiocarbonates using a chloride ion exchange resin [40] and it can be assumed that they used the products for their above mentioned study. Here, a hydroxy-functionalized exchange resin was employed directly [41], whose capacity was measured by titration with hydrochloric acid prior to use in order to be able to add the stoichiometrically exact amount of hydroxide ions to the system. The fact that the solubility of the produced trithiocarbonates in carbon disulfide decreased with increasing chain length enabled the possibility of fractionating them directly within the work-up of the reaction by first washing the resin with carbon disulfide and then with THF.

Figure 1. General structure of the employed RAFT agents.

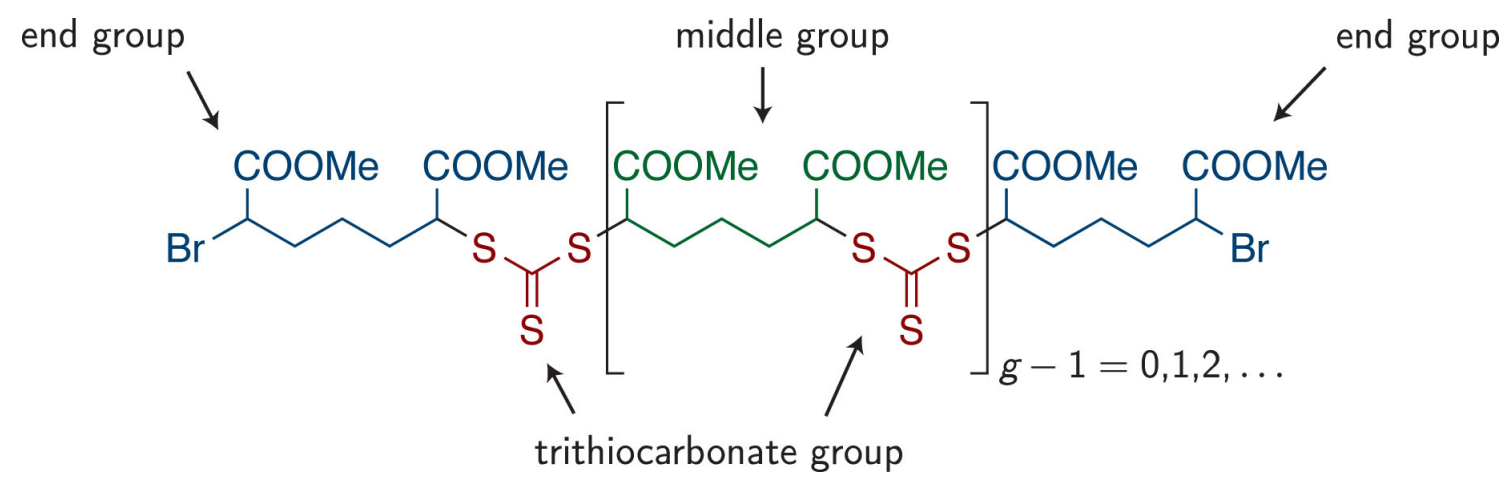

The prepared trithiocarbonates were examined by means of SEC. The theoretically expected positions of the individual low molar mass peaks in the SEC curves of the polytrithiocarbonates, which correlate to the individual degrees of polymerization, can be rationalized on the basis of their general structure which is shown in Figure 1:

$$
\begin{aligned}
\bar{M}_{\mathrm{n}, \mathrm{RAFT}} & =\bar{g} M_{\mathrm{TTC}}+2 M_{\mathrm{EG}}+(\bar{g}-1) M_{\mathrm{MG}} \\
& =346.01 \mathrm{~g} \mathrm{~mol}^{-1}+\bar{g} \cdot 294.42 \mathrm{~g} \mathrm{~mol}^{-1} .
\end{aligned}
$$

$\bar{M}_{\mathrm{n}, \mathrm{RAFT}}$ is the average molar mass of the RAFT agents with an average of $\bar{g}$ trithiocarbonate groups, $M_{\mathrm{TTC}}, M_{\mathrm{EG}}$ and $M_{\mathrm{MG}}$ are the molar masses of trithiocarbonate groups, end groups and middle groups (see Figure 1).

Because no appropriate calibration data were available, the SEC curves were measured using the calibration for linear polystyrene. The SEC curve of polyfunctional RAFT agent A (see Table 1), which was synthesized via procedure 1, is shown in Figure 2(a). The numbers in the diagram indicate the positions of the maxima in the number-weighted distribution. The UV detector signal-measured at $310 \mathrm{~nm}$, where trithiocarbonates are known to absorb radiation [41] — nicely matches the refractive index (RI) detector signal. This indicates that molecules with higher masses possess more trithiocarbonate groups [44], which is also underlined by the expected structure of almost equidistant peaks. The first 
peak, though, can only be seen in the RI signal wherefore it has to be assigned to a reactant or a byproduct without trithiocarbonate groups. For the analysis of all SEC curves, the peak at $387 \mathrm{~g} \mathrm{~mol}^{-1}$ was the first one that was considered. Comparing the positions of the peaks with the expected ones, it can be seen that the measured absolute positions and the distances between the peaks are considerably lower than the theoretical values, most likely due to the non-appropriate calibration. Nevertheless, the measured average molar masses of the prepared RAFT agents were used to calculate their average number of trithiocarbonate groups according to Equation (1). It has to be kept in mind that these values are only a rough approximation and probably too low. For polytrithiocarbonate $\mathbf{A}$ this yields an average number of $\bar{g}_{\mathrm{GPC}, \mathrm{A}}=1.34$ trithiocarbonate groups per chain. Figure 2(b) shows the SEC curves of the polyfunctional RAFT agents $\mathbf{C}$ and $\mathbf{D}$ (see Table 1) that were prepared within the same reaction performed according to procedure 2. $\mathbf{C}$ was obtained by rinsing with $\mathbf{C S}_{2}$ and $\mathbf{D}$ by rinsing with THF. These curves illustrate that by procedure 2, RAFT agents with higher degree of polymerization could be produced than with procedure 1 and that the fractionation of the reaction products was successful. Again, the good agreement of the RI signal and the UV signal demonstrates that molecules with higher molar mass also possess more trithiocarbonate groups, which is in line with the structural expectations. Generally, SEC analysis gave values of $\bar{g}_{\mathrm{GPC}}=4.09-5.33$ for the fraction obtained by rinsing with $\mathrm{CS}_{2}$ and $\bar{g}_{\mathrm{GPC}}=12.0-18.5$ for the fraction obtained by rinsing with THF.

Table 1. Overview of polyfunctional RAFT agents that were employed for further polymerizations in this study with synthesis method, average numbers of TTC groups $\bar{g}$ and number average molar masses $\bar{M}_{\mathrm{n}}$, determined via SEC and NMR. The last column indicates the polymerization in which they were employed (see Tables 2 and 3) and, in parentheses, the copolymerization for which the respective polymerization products were used.

\begin{tabular}{|c|c|c|c|c|c|c|c|}
\hline polyRAFT & synthesis & fraction & $\bar{M}_{\mathrm{n}, \mathrm{SEC}}$ & $\bar{g}_{\mathrm{SEC}}{ }^{*}$ & $\bar{M}_{\mathrm{n}, \mathrm{NMR}}{ }^{\dagger}$ & $\bar{g}_{\mathrm{NMR}}$ & used for \\
\hline $\mathbf{A}$ & procedure 1 & - & $7.41 \times 10^{2}$ & 1.34 & $\left(6.40 \times 10^{2}\right)$ & $1^{\ddagger}$ & $\mathbf{1}(\rightarrow \mathbf{I})$ \\
\hline B & procedure 2 & $\mathrm{CS}_{2}$ & $1.66 \times 10^{3}$ & 4.46 & $1.55 \times 10^{3}$ & 4.09 & $\mathbf{2}(\rightarrow \mathbf{I I}), \mathbf{7}$ \\
\hline $\mathbf{C}$ & procedure 2 & $\mathrm{CS}_{2}$ & $1.57 \times 10^{3}$ & 4.16 & $1.38 \times 10^{3}$ & 3.50 & 3, $4(\rightarrow$ III $), 8$ \\
\hline D & procedure 2 & THF & $5.43 \times 10^{3}$ & 17.3 & $5.03 \times 10^{3}$ & 15.9 & $5(\rightarrow$ IV $), 9$ \\
\hline $\mathbf{E}$ & procedure 2 & THF & $3.87 \times 10^{3}$ & 12.0 & $2.76 \times 10^{3}$ & 8.19 & $\mathbf{6}(\rightarrow \mathbf{V}, \mathbf{V I})$ \\
\hline & & & A value un & 1 was $n$ & \multicolumn{3}{|c|}{$\begin{array}{l}{ }^{*} \text { Calculated from } \bar{M}_{\mathrm{n}, \mathrm{SEC}} \text { by Equation (1). } \\
\quad{ }^{\dagger} \text { Calculated from } \bar{g}_{\mathrm{NMR}} \text { by Equation (2). } \\
\text { sured, presumably due to residue dibromide. }\end{array}$} \\
\hline
\end{tabular}

It was already shown by You et al. that the average number of trithiocarbonate groups within the prepared polyfunctional RAFT agents can also be determined by measuring their NMR spectra and calculating the ratio of the intensity $I_{4.7} \mathrm{ppm}$ at $4.7 \mathrm{ppm}$ (proton in $\alpha$-position to a trithiocarbonate group) and the intensity $I_{4.2 \mathrm{ppm}}$ at $4.2 \mathrm{ppm}$ (proton in $\alpha$-position to a bromine atom) [40]:

$$
\bar{g}_{\mathrm{NMR}}=\frac{I_{4.7 \mathrm{ppm}}}{I_{4.2 \mathrm{ppm}}}
$$

The thus determined value for polytrithiocarbonate A lies under the minimum value of 1, which can possibly be explained by residual dibromide in the sample contributing only to $I_{4.2 \mathrm{ppm}}$. This is 
a considerable factor of inaccuracy of this method when polytrithiocarbonates with low degree of polymerization are examined. On the other hand, also the examination of trithiocarbonates with a very high number of trithiocarbonate groups becomes very unprecise because in these cases, it has to be divided by very small values of $I_{4.2 \mathrm{ppm}}$. The determined average numbers of trithiocarbonate groups for procedure 2 were $\bar{g}_{\mathrm{NMR}}=2.89-4.09$ for the $\mathrm{CS}_{2}$ fraction and $\bar{g}_{\mathrm{NMR}}=8.19-15.9$ for the THF fraction (see Table 1).

To make sure that complete relaxation of all nuclei was achieved within the NMR measurements, one polytrithiocarbonate sample was re-measured with an additional relaxation delay of 15 seconds between the pulses. This measurement gave an identical spectrum which demonstrates that the spectra can indeed be interpreted quantitatively.

Figure 2. (a) SEC curve (solid line: RI signal, dashed line: UV signal) of the polyfunctional RAFT agent A; (b) SEC curves (solid lines: RI signal, dashed lines: UV signal) of the polyfunctional RAFT agents $\mathbf{C}$ (red, obtained by rinsing with $\mathrm{CS}_{2}$ ) and $\mathbf{D}$ (black, obtained by rinsing with THF).
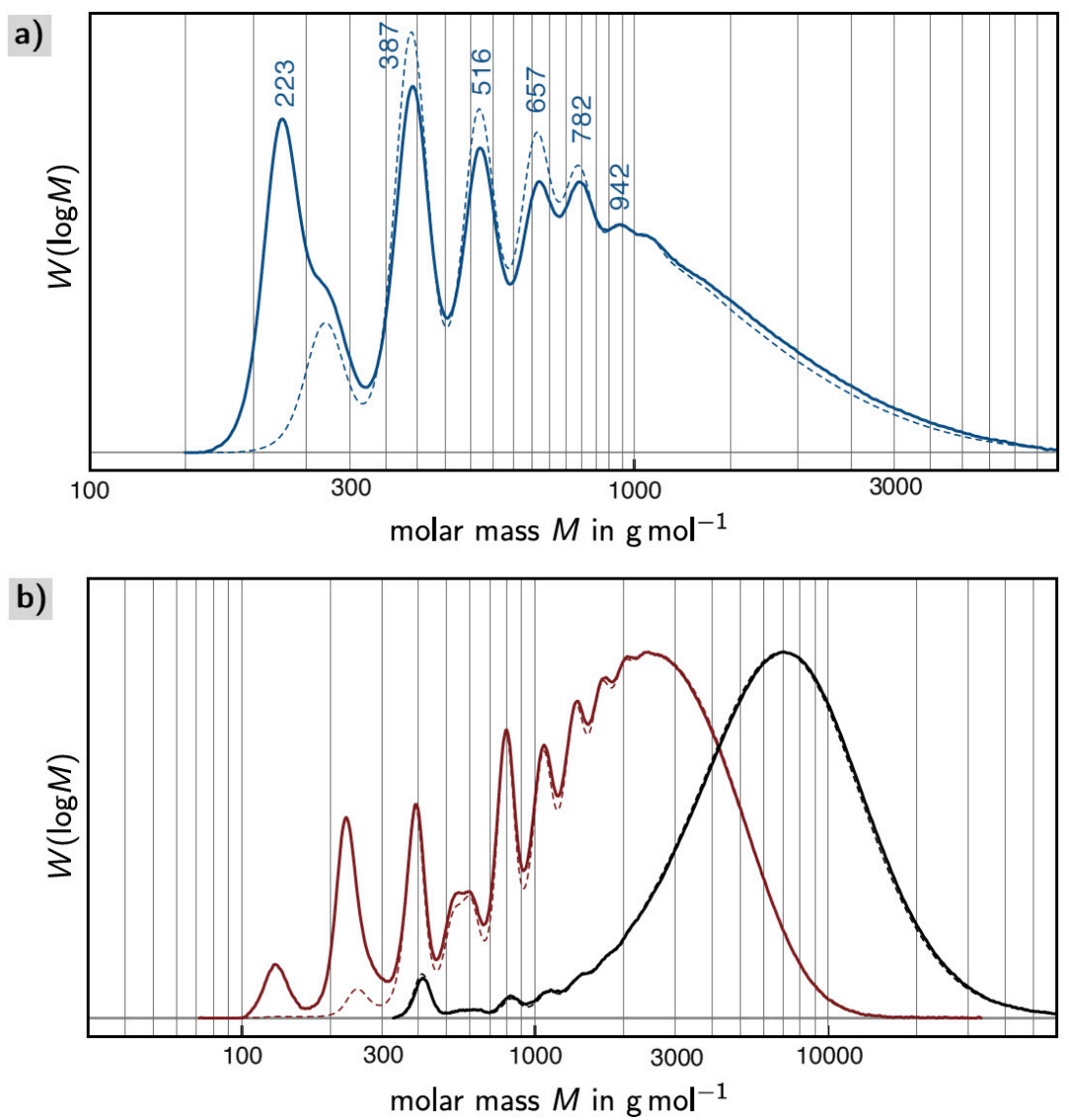

\subsection{Polymerizations}

In order to produce segmented copolymers of styrene and BA, styrene is preferentially used for the first polymerization step, as macromolecular RAFT agents with the better leaving groups are formed. Nevertheless, to gain more insight into the system, three polytrithiocarbonates were also employed in polymerizations with BA. All homopolymerizations were performed in bulk and initiated thermally 
with AIBN as initiator. The resulting polymers were examined by SEC (see Tables 2 and 3) using the calibration data for the pure homopolymers which seem reasonably well applicable since the RAFT agents constitute only a minor part of the final polymer's main chain.

Table 2. Bulk polymerizations of styrene with different polyfunctional RAFT agents at $60^{\circ} \mathrm{C}$ and ambient pressure using AIBN as initiator. The table lists the individual experimental conditions, the gravimetrically determined monomer conversions of the samples, and the corresponding $\bar{M}_{\mathrm{n}}$ and polydispersity indices (PDI) obtained by the RI and the UV detector.

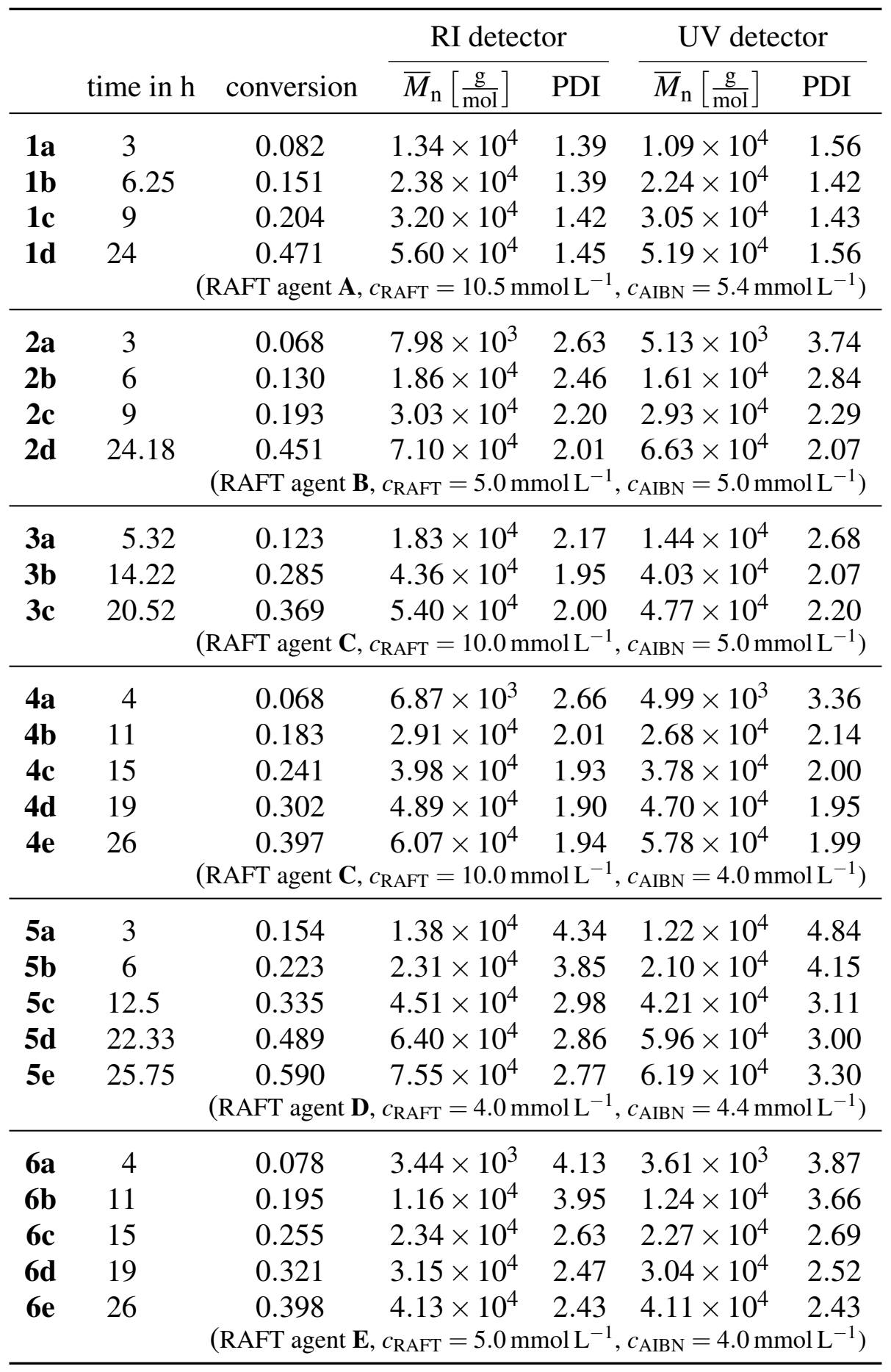


Table 3. Bulk polymerizations of $n$-butyl acrylate with different polyfunctional RAFT agents at $60^{\circ} \mathrm{C}$ and ambient pressure using AIBN as initiator. The table lists the individual experimental conditions, the gravimetrically determined monomer conversions of the samples, and the corresponding $\bar{M}_{\mathrm{n}}$ and polydispersity indices (PDI) obtained by the RI and the UV detector.

\begin{tabular}{|c|c|c|c|c|c|c|}
\hline & \multirow[b]{2}{*}{ time in $\mathrm{h}$} & \multirow[b]{2}{*}{ conversion } & \multicolumn{2}{|c|}{ RI detector } & \multicolumn{2}{|c|}{ UV detector } \\
\hline & & & $\bar{M}_{\mathrm{n}}\left[\frac{\mathrm{g}}{\mathrm{mol}}\right]$ & PDI & $\bar{M}_{\mathrm{n}}\left[\frac{\mathrm{g}}{\mathrm{mol}}\right]$ & PDI \\
\hline \multirow[t]{2}{*}{$7 \mathbf{a}$} & 2.5 & 0.783 & $9.80 \times 10^{4}$ & 3.80 & $7.04 \times 10^{4}$ & 4.81 \\
\hline & & \multicolumn{5}{|c|}{$\left(\mathrm{RAFT}\right.$ agent $\left.\mathbf{B}, c_{\mathrm{RAFT}}=5.0 \mathrm{mmol} \mathrm{L}^{-1}, c_{\mathrm{AIBN}}=5.0 \mathrm{mmol} \mathrm{L}^{-1}\right)$} \\
\hline $\mathbf{8 a}$ & 0.5 & 0.042 & $5.26 \times 10^{3}$ & 2.73 & $1.96 \times 10^{3}$ & 4.98 \\
\hline $8 b$ & 1 & 0.109 & $7.26 \times 10^{3}$ & 6.09 & $7.24 \times 10^{3}$ & 5.57 \\
\hline $8 c$ & 1.5 & 0.389 & $1.03 \times 10^{5}$ & 2.08 & $9.77 \times 10^{4}$ & 2.11 \\
\hline $8 d$ & 2 & 0.762 & $1.97 \times 10^{5}$ & 2.23 & $1.87 \times 10^{5}$ & 2.21 \\
\hline \multirow[t]{2}{*}{$8 \mathbf{e}$} & 2.5 & 0.814 & $2.08 \times 10^{5}$ & 2.19 & $1.98 \times 10^{5}$ & 2.25 \\
\hline & & \multicolumn{5}{|c|}{$\left(\right.$ RAFT agent $\left.\mathbf{C}, c_{\mathrm{RAFT}}=10.0 \mathrm{mmol} \mathrm{L}^{-1}, c_{\mathrm{AIBN}}=5.0 \mathrm{mmol} \mathrm{L}^{-1}\right)$} \\
\hline $9 \mathbf{a}$ & 0.67 & 0.008 & $1.24 \times 10^{3}$ & 2.73 & $1.13 \times 10^{3}$ & 2.53 \\
\hline $9 \mathrm{~b}$ & 1.5 & 0.121 & $4.98 \times 10^{3}$ & 12.30 & $3.16 \times 10^{3}$ & 14.70 \\
\hline 9c & 2 & 0.325 & $1.08 \times 10^{4}$ & 22.50 & $2.24 \times 10^{4}$ & 11.00 \\
\hline 9d & 2.75 & 0.581 & $1.43 \times 10^{4}$ & 32.80 & $5.73 \times 10^{4}$ & 8.21 \\
\hline \multirow[t]{2}{*}{$9 e$} & 3.15 & 0.664 & $1.74 \times 10^{4}$ & 31.50 & $3.72 \times 10^{4}$ & 14.70 \\
\hline & & \multicolumn{5}{|c|}{$\left(\mathrm{RAFT}\right.$ agent $\left.\mathbf{D}, c_{\mathrm{RAFT}}=3.0 \mathrm{mmol} \mathrm{L}^{-1}, c_{\mathrm{AIBN}}=3.0 \mathrm{mmol} \mathrm{L}^{-1}\right)$} \\
\hline
\end{tabular}

In all polymerizations, the molar masses grow linearly with monomer conversion, which underlines the living character of the systems and demonstrates the possibility to synthesize polymers with precisely specifiable block lengths up to very high molar masses. The degree of control, however, seems to be higher for the polymerizations of styrene. Here, products with lower PDIs were obtained. Within the individual polymerizations, the PDIs decrease to a rather constant value after the initial period of the polymerization. Exemplarily, a plot of $\bar{M}_{\mathrm{n}}$ and the PDI (RI signal) as a function of monomer conversion along with the corresponding SEC curves are shown for polymerization 4 in Figure 3.

The general tendency can be observed that RAFT agents with more trithiocarbonate groups lead to polymers with higher PDIs. This finding, however, does not mean that these RAFT agents exert a lower control over the polymerizations, but is just what one would expect theoretically as we could show elsewhere based on the ideally expected distributions of the generated polymers [37]. The absolute PDI values are higher than those usually obtained in RAFT polymerizations because the molar mass distributions consist of several overlaying peaks with lower dispersity for each number of blocks. These individual peaks could partially be resolved when RAFT agents with low numbers of functional groups were employed (see below).

For the second polymerization step of the examined synthesis strategy, several prepared styrene polymers were employed as macromolecular RAFT agents in radical polymerizations of BA. The experimental conditions were comparable to those of the first polymerization step, except for the fact that the polymerizations were conducted in toluene because the solubility of the macromolecular styrene 
polymers in BA is rather low. The experimental results of all copolymerizations are listed in Table 4. It has to be noted that, for lack of appropriate SEC calibration data for the produced multiblock homopolymers, the calibration for linear polystyrene was used and the SEC curves and the data gained therefrom cannot be seen at all as fully correct. (In some cases even molar masses lower than those of the employed macromolecular RAFT agents were obtained.) The given mass ratios $r_{\mathrm{S} / \mathrm{BA}}$ of styrene and BA units in the polymers were calculated on the basis of the gravimetrically determined monomer conversions and are therefore not affected by this error. Figure 4 shows the SEC curves for all samples of copolymerization III. It can be seen that the molar masses clearly grow with monomer conversion, independently of the number of trithiocarbonate groups in the macromolecular RAFT agent. It is especially remarkable here that no tailing can be seen in the SEC curves, which, due to incomplete reinitiation, is a typical feature in the SEC curves of RAFT-prepared copolymers with only two segments. This finding may be accounted to the fact that most polymer chains comprise several trithiocarbonate groups which makes it very likely that the reinitiation takes place at least at one of them. Accordingly, the dispersities of all produced multiblock copolymers are relatively low.

Figure 3. (a) $\bar{M}_{\mathrm{n}}$ (black circles) and polydispersity index (PDI, red squares, RI signal) as a function of monomer conversion for polymerization 4; dashed line: linear regression for $\bar{M}_{\mathrm{n}}$; (b) Corresponding SEC curves (solid lines: RI signal, dashed lines: UV signal) and SEC curve of the employed RAFT agent $\mathbf{C}$.
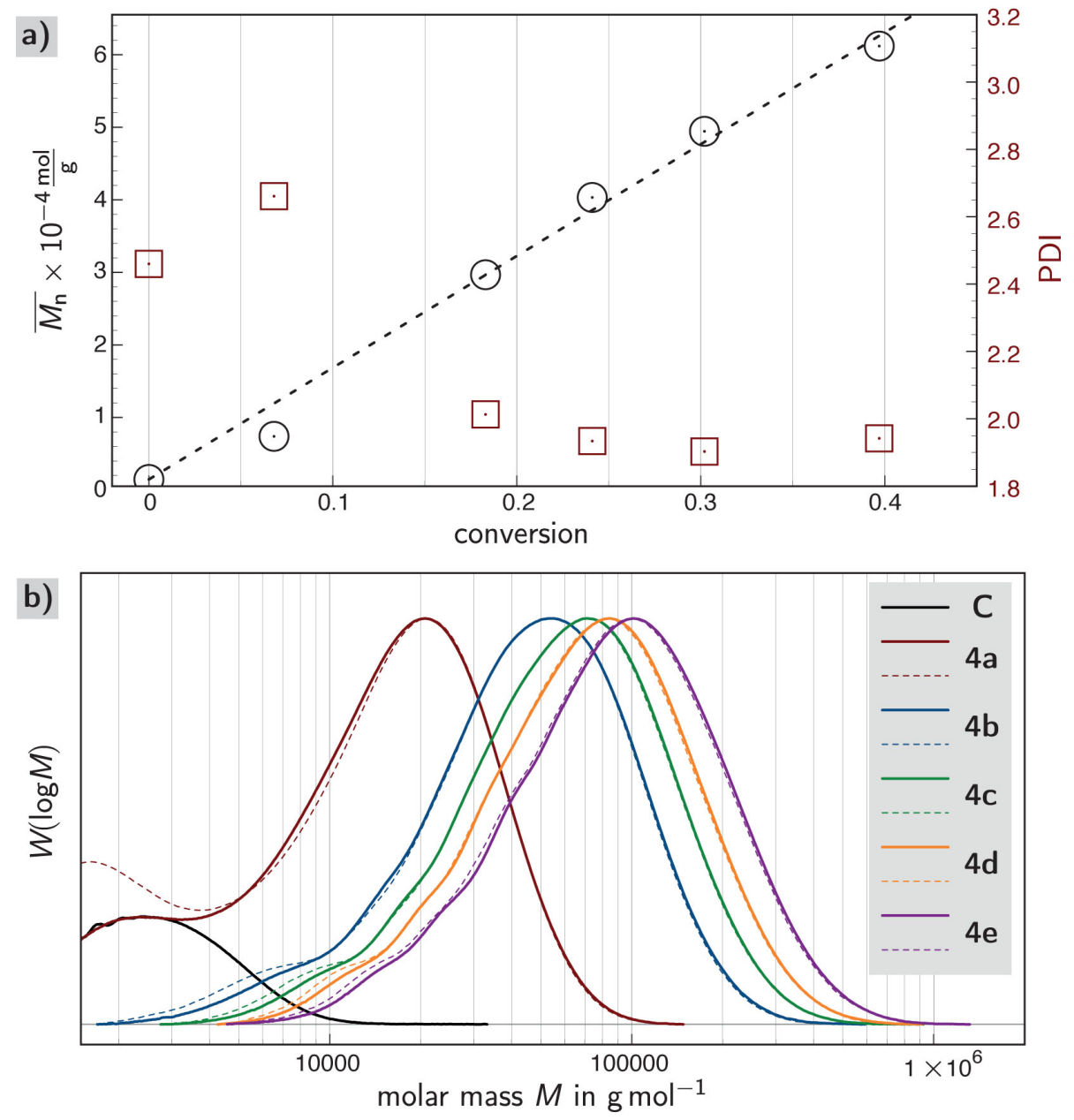
Table 4. Copolymerizations of $n$-butyl acrylate with different styrene macroRAFT agents in solution of toluene at $60^{\circ} \mathrm{C}$ and ambient pressure using AIBN as initiator. The table lists the individual experimental conditions, the gravimetrically determined monomer conversions of the samples, and the corresponding $\bar{M}_{\mathrm{n}}$ and polydispersity indices (PDI) obtained by the RI and the UV detector. $\phi_{\mathrm{M}}$ is the volume fraction of the monomer in the polymerization mixture, $r_{\mathrm{S} / \mathrm{BA}}$ is the gravimetrically determined mass ratio of styrene and BA in the polymers. SEC data were obtained with calibration for pure linear polystyrene.

\begin{tabular}{|c|c|c|c|c|c|c|c|}
\hline & \multirow[b]{2}{*}{ time in $\mathrm{h}$} & \multirow[b]{2}{*}{ conversion } & \multirow[b]{2}{*}{$r_{\mathrm{S} / \mathrm{BA}}$} & \multicolumn{2}{|c|}{ RI detector } & \multicolumn{2}{|c|}{ UV detector } \\
\hline & & & & $\bar{M}_{\mathrm{n}}\left[\frac{\mathrm{g}}{\mathrm{mol}}\right]$ & PDI & $\bar{M}_{\mathrm{n}}\left[\frac{\mathrm{g}}{\mathrm{mol}}\right]$ & PDI \\
\hline Ia & 1.5 & 0.118 & 1.79 & $4.65 \times 10^{4}$ & 1.61 & $5.18 \times 10^{4}$ & 1.47 \\
\hline Ib & 3 & 0.306 & 0.689 & $6.25 \times 10^{4}$ & 1.80 & $8.13 \times 10^{4}$ & 1.43 \\
\hline \multirow[t]{2}{*}{ Ic } & 5 & 0.634 & 0.333 & $8.46 \times 10^{4}$ & 1.93 & $8.95 \times 10^{4}$ & 1.81 \\
\hline & \multicolumn{7}{|c|}{$\left(\right.$ RAFT agent $\left.1 \mathbf{c} \phi_{\mathrm{M}}=0.5, c_{\mathrm{RAFT}}=3.0 \mathrm{mmol} \mathrm{L}^{-1}, c_{\mathrm{AIBN}}=2.0 \mathrm{mmol} \mathrm{L}^{-1}\right)$} \\
\hline IIa & 2 & 0.110 & 1.82 & $4.80 \times 10^{4}$ & 2.17 & $4.84 \times 10^{4}$ & 2.15 \\
\hline IIb & 4 & 0.286 & 0.325 & $6.81 \times 10^{4}$ & 2.25 & $6.45 \times 10^{4}$ & 2.29 \\
\hline \multirow[t]{2}{*}{ IIc } & 6 & 0.521 & 0.178 & $8.66 \times 10^{4}$ & 2.36 & $9.62 \times 10^{4}$ & 2.08 \\
\hline & \multicolumn{7}{|c|}{$\left(\right.$ RAFT agent $\left.2 \mathbf{c}, \phi_{\mathrm{M}}=0.5, c_{\mathrm{RAFT}}=3.0 \mathrm{mmol} \mathrm{L}^{-1}, c_{\mathrm{AIBN}}=2.0 \mathrm{mmol} \mathrm{L}^{-1}\right)$} \\
\hline IIIa & 3.5 & 0.101 & 1.55 & $7.74 \times 10^{4}$ & 2.10 & $7.25 \times 10^{4}$ & 2.21 \\
\hline IIIb & 4.5 & 0.143 & 1.09 & $8.84 \times 10^{4}$ & 1.94 & $8.20 \times 10^{4}$ & 2.01 \\
\hline IIIc & 7 & 0.276 & 0.567 & $1.16 \times 10^{5}$ & 1.93 & $1.05 \times 10^{5}$ & 2.02 \\
\hline \multirow[t]{2}{*}{ IIId } & 9.5 & 0.433 & 0.361 & $1.42 \times 10^{5}$ & 1.92 & $1.34 \times 10^{5}$ & 1.96 \\
\hline & \multicolumn{7}{|c|}{$\left(\right.$ RAFT agent $\left.4 \mathrm{~d}, \phi_{\mathrm{M}}=0.5, c_{\mathrm{RAFT}}=1.43 \mathrm{mmol} \mathrm{L}^{-1}, c_{\mathrm{AIBN}}=1 \mathrm{mmol} \mathrm{L}^{-1}\right)$} \\
\hline IVa & 1.5 & 0.000 & - & $5.94 \times 10^{4}$ & 2.58 & $5.70 \times 10^{4}$ & 2.61 \\
\hline IVb & 2.5 & 0.000 & - & $5.07 \times 10^{4}$ & 2.59 & $4.82 \times 10^{4}$ & 2.61 \\
\hline IVc & 4 & 0.022 & 8.06 & $5.35 \times 10^{4}$ & 2.66 & $5.12 \times 10^{4}$ & 2. \\
\hline IVd & 6 & 0.058 & 2.98 & $6.79 \times 10^{4}$ & 2.55 & $6.47 \times 10^{4}$ & 2.66 \\
\hline \multirow[t]{2}{*}{ IVe } & 9 & 0.145 & 1.20 & $1.03 \times 10^{5}$ & 2.32 & $1.01 \times 10^{5}$ & 2.35 \\
\hline & \multicolumn{7}{|c|}{$\left(\right.$ RAFT agent $\left.5 \mathbf{d}, \phi_{\mathrm{M}}=0.5, c_{\mathrm{RAFT}}=1.23 \mathrm{mmol} \mathrm{L}^{-1}, c_{\mathrm{AIBN}}=0.67 \mathrm{mmol} \mathrm{L}^{-1}\right)$} \\
\hline Va & 1.5 & 0.007 & 16.5 & $1.53 \times 10^{4}$ & 2.64 & $1.42 \times 10^{4}$ & 2.79 \\
\hline $\mathbf{V b}$ & 2.5 & 0.033 & 3.59 & $2.16 \times 10^{4}$ & 2.58 & $2.06 \times 10^{4}$ & 2.67 \\
\hline Vc & 4 & 0.082 & 1.46 & $3.31 \times 10^{4}$ & 2.48 & $3.11 \times 10^{4}$ & 2.59 \\
\hline Vd & 6 & 0.170 & 0.699 & $5.67 \times 10^{4}$ & 2.22 & $5.53 \times 10^{4}$ & 2.23 \\
\hline \multirow[t]{2}{*}{ Ve } & 9 & 0.357 & 0.334 & $9.76 \times 10^{4}$ & 2.04 & $9.44 \times 10^{4}$ & 2.07 \\
\hline & \multicolumn{7}{|c|}{$\left(\mathrm{RAFT}\right.$ agent $\left.\mathbf{6 c}, \phi_{\mathrm{M}}=0.4, c_{\mathrm{RAFT}}=1.85 \mathrm{mmol} \mathrm{L}^{-1}, c_{\mathrm{AIBN}}=0.8 \mathrm{mmol} \mathrm{L}^{-1}\right)$} \\
\hline VIa & 3 & 0.097 & 1.25 & $5.50 \times 10^{4}$ & 2.48 & $5.19 \times 10^{4}$ & 2.60 \\
\hline VIb & 4 & 0.152 & 0.800 & $7.46 \times 10^{4}$ & 2.41 & $7.15 \times 10^{4}$ & 2.47 \\
\hline VIc & 5.5 & 0.257 & 0.474 & $1.07 \times 10^{5}$ & 2.35 & $1.05 \times 10^{5}$ & 2.45 \\
\hline \multirow[t]{2}{*}{ VId } & 9 & 0.628 & 0.194 & $1.91 \times 10^{5}$ & 2.22 & $1.81 \times 10^{5}$ & 2.27 \\
\hline & \multicolumn{7}{|c|}{$\left(\right.$ RAFT agent $\left.6 \mathbf{d} \phi_{\mathrm{M}}=0.33, c_{\mathrm{RAFT}}=2.3 \mathrm{mmol} \mathrm{L}^{-1}, c_{\mathrm{AIBN}}=1.33 \mathrm{mmol} \mathrm{L}^{-1}\right)$} \\
\hline
\end{tabular}


Figure 4. SEC curves (solid lines: RI signal, dashed lines: UV signal, calibration for polystyrene) for copolymerization III.

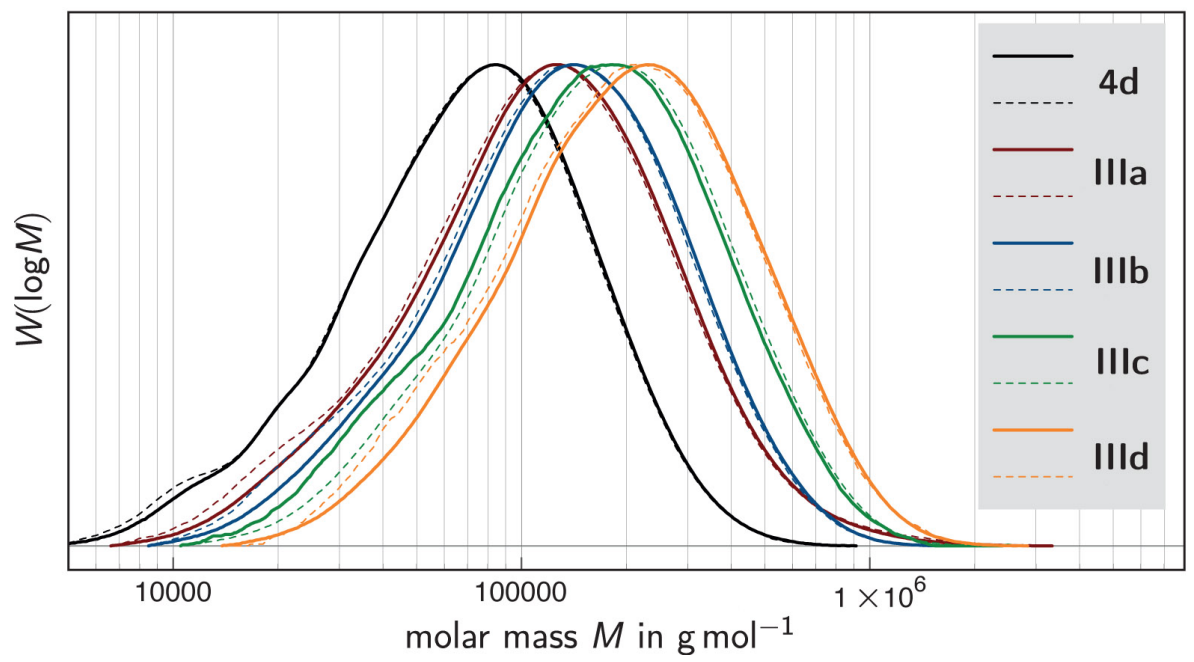

\subsection{Analysis of the Prepared Polymers}

The multiblock polymers and copolymers were cleaved at the trithiocarbonate groups in order to compare the molar masses of the polymers prior to $\left(\bar{M}_{\mathrm{n}, 0}\right)$ and after $\left(\bar{M}_{\mathrm{n}, 1}\right)$ the cleavage. Ideally, the average number of trithiocarbonate groups would then be calculable by

$$
\bar{g}=\frac{\bar{M}_{\mathrm{n}, 0}}{\bar{M}_{\mathrm{n}, 1}}-1
$$

The here used approach for the cleavage was the aminolysis reaction with $n$-butyl amine which leads to thiol-capped polymer chains. However, when cleaving multiblock polymers of only styrene, the oxidative coupling to longer polymers with disulfide bridges along their chain [45] could be observed (non-UV-active peak at double molar masses). To prevent this unwanted reaction, Lima et al. [46] presented a two-step strategy which was subsequently improved to a one-pot reaction by Qiu and Winnik [42]. It involves the "sealing" of the thiol groups by the Michael addition to a BA molecule directly after the aminolysis in the presence of the reducing agent tris(2-carboxyethyl) phosphine hydrochloride. With this procedure the coupling could indeed be prevented. However, the coupling reaction did not occur when polymers with BA segments next to the trithiocarbonate groups were subjected to the aminolysis so that the procedure of Qui and Winnik was not necessary in these cases. The same finding was made by others when cleaving polymethylmethacrylate polymers [46,47]. Xu et al. proposed an intramolecular cyclization reaction of the thiols with the ester groups of the adjacent polymer chain that is faster than the intermolecular coupling as an explanation for this phenomenon [48]. Because of the structural similarity of BA it seems reasonable to suppose that the analogous reaction takes place here.

Figure 5 shows the SEC curves of three styrene multiblock polymers that were prepared using polyfunctional RAFT agents with different average number of trithiocarbonate groups and the SEC curves of the corresponding cleavage products. The numbers in the diagrams indicate the positions of the maxima in the number-weighted molar mass distributions. Polymer 1d (Figure 5(a)) was prepared from trithiocarbonate $\mathbf{A}$ with the lowest number of functional groups (1.34, measured via SEC). Individual peaks for molecules with two, three and four blocks with maxima at 45,000, 94,000 and 150,000 $\mathrm{g} \mathrm{mol}^{-1}$ 
are resolved here. The SEC curve of the cleaved polymers shows that they have clearly lower molar masses but still features two individual peaks at 27,000 and 50,000 $\mathrm{g} \mathrm{mol}^{-1}$. This is due to the fact that not all blocks within the multiblock polymers have the same length. Two types of blocks can be distinguished that cannot be interconverted into each other during the polymerization: those in the middle of the polymer chains, connected to trithiocarbonate groups on both sides, and those at the end of the polymer chains, which are connected to only one trithiocarbonate group. The first will be denoted "middle blocks" and the latter "end blocks". In our theoretical study [37], we could demonstrate that the ratio of the average masses of middle and end blocks lies between 1 and 2, depending on the occurring mechanism, that is, the middle blocks are expected to have higher masses. Thus, the peak at higher molar masses can be assigned to the middle blocks and the one at lower masses to the end blocks. With that assignment, the peak positions of the maxima add up very well, having in mind that every block polymer consists of two end blocks and all other blocks are middle blocks. When cleaving polymers with a higher average number of blocks, the SEC curve of the cleavage products should show a more intense peak at higher molar masses for the middle blocks and a less intense peak for the end blocks. Figure 5(b), which shows the aminolysis of polymer $\mathbf{2 d}$ (5.46 blocks in average according to the SEC determined value), shows that this is indeed the case. Again, the positions of the maxima of the number-weighted distributions add up very well here. In the case that polymers with even more blocks are cleaved, the peak for the end blocks is no longer visible. This is demonstrated in Figure 5(c), showing the aminolysis of polymer 5d (18.3 average blocks according to the SEC value), which had a PDI of 2.86. The cleaved polymers by contrast have a PDI of only 1.18 , which is lower than that of the other two cleavage products, obviously because there are less end groups which increase the dispersity. These results emphasize that the dispersity of the multiblock polymers is due to the distribution of blocks, rather than the broadness of the mass distributions of the individual blocks. Generally, a correlation of the average number of blocks obtained by aminolysis and the number of blocks in the utilized RAFT agents could be observed, although the first number was always lower than the latter (for low average block numbers even lower than the minimum value of 2). This held also true for the BA multiblock homopolymers.

The aminolysis of the prepared multiblock copolymers leads to the formation of polymers with three segments (the former "middle blocks") and of polymers with two segments (the former "end blocks"). These reactions also yielded polymers with clearly lower molar masses and the decrease of the masses correlated to the number of trithiocarbonate groups in the initial RAFT agent.

Selected multiblock copolymer samples were preliminarily analyzed via DSC. Figure 6 shows the DSC curves of the polymer samples $\mathbf{6 c}$ and $\mathbf{V a}-\mathbf{V d}$. In the curve of the styrene homopolymer $\mathbf{6 c}$ (13 average blocks according to the SEC analysis of the employed RAFT agent), a baseline step can be observed that is caused by the glass transition of the polymer. It can be seen that the glass transition temperature $\left(T_{\mathrm{g}, \mathbf{6 c}}=344 \mathrm{~K}\right)$ is lowered with respect to the one of pure linear polystyrene $\left(T_{\mathrm{g}, \mathrm{PS}}=373 \mathrm{~K}\right)$ [49], which could speculatively be explained by the easier rotatability of the components of the employed RAFT agent that are incorporated along the main chain. With increasing content of poly(n-butyl acrylate), which has a lower glass transition temperature $\left(T_{\mathrm{g}, \mathrm{PBA}}=219 \mathrm{~K}\right)$ [49], the signal in the DSC curves is shifted to lower temperatures. This drop of $T_{\mathrm{g}}$ implies that the material is increasingly plasticized by the increasing amounts of poly(n-butyl acrylate), which is not expected for clean microphase separated polymer domains, for which two constant $T_{\mathrm{g}}$ values should be observable. It should be noted here that the polymer material 
was not annealed specifically for prolonged times and microphase separation may thus not have evolved in the material. It is well anticipated that the phase separation process of these multiblock copolymers is very slow, due to the multitude of individual segments sitting along a well-entangled polymer chain, which clearly hampers the diffusion of individual segments in the polymer melt.

Figure 5. (a) SEC curves of polymer 1d before (dashed line) and after (solid line) aminolysis; (b) SEC curves of polymer $\mathbf{2 d}$ before (dashed line) and after (solid line) aminolysis. (The numbers in the diagrams indicate the maxima of the number-weighted distributions.); (c) SEC curves of polymer $\mathbf{5 d}$ before (dashed line) and after (solid line) aminolysis.

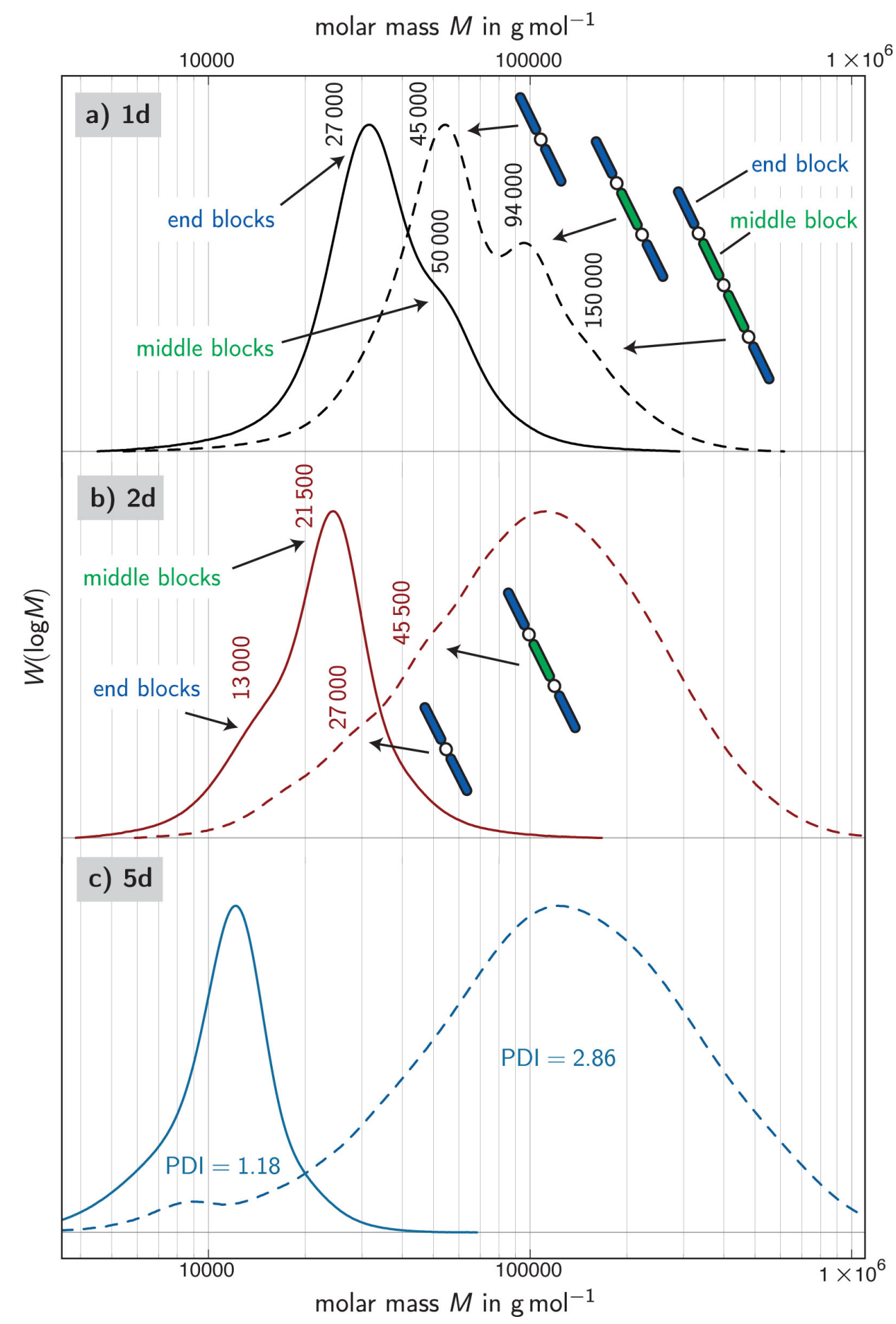


Figure 6. DSC curves of polymer samples $\mathbf{6 c}$ and Va-Vd; curves are shifted vertically for clarity.

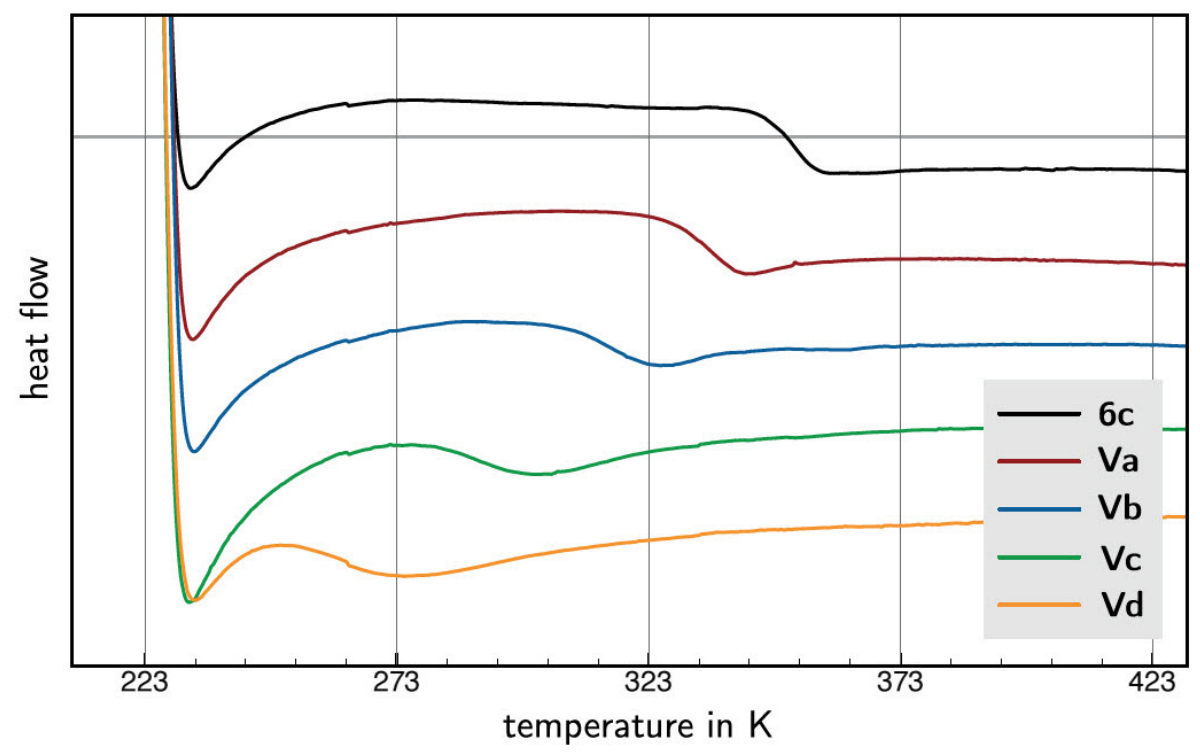

\section{Conclusions}

As mentioned in the beginning, the presented study was set up in order to examine to what extent the synthesis of multiblock copolymers with polyfunctional RAFT agents, which are employed in two subsequent polymerizations, meets the initially listed methodological criteria for an advantageous synthesis strategy. The presented results—along with the above cited publications in this field—indicate that indeed most criteria are met very well by this strategy. It is easy to implement as the polyfunctional RAFT agent, carrying multiple trithiocarbonate groups, could be synthesized in a one-pot reaction, which did not require any chromatographic purification steps, from commercially available compounds. Only two further radical polymerization steps with the very common initiator AIBN were necessary to successfully produce polymers with long segments. Via cleavage of the multiblock polymers at the trithiocarbonate groups and SEC analysis of the cleavage products, it could be demonstrated that the blocks in the middle of the multiblock polymers have very homogeneous lengths and it could be observed for the first time that the blocks at the ends of the polymers, which cannot be interconverted into middle blocks during the polymerization, have lower masses than those in the middle. How the mass ratio of these different block types can be used to gain information about the ongoing mechanism and the RAFT process in general, was already shown by us in another publication [37]. It was found that the number of alternating segments in the produced polymers corresponds directly to the number of trithiocarbonate groups in the initial RAFT agent and can therefore be controlled by using a polytrithiocarbonate with the desired degree of polymerization. It is envisaged that the number of alternating segments can be exactly tuned by using a mixture of different RAFT agents in the correct proportion. As predicted theoretically [37], the distribution of alternating segments within the generated polymers was relatively narrow. Because of the great universality and tolerance towards functional groups of RAFT polymerization, it is envisaged that the examined strategy will also be deployable for polymerizations of numerous other monomers and that it can be scaled up to industrial dimensions. From our results we conclude that the studied method is a 
very potent and convenient way to produce multiblock copolymers, which appears to be superior to the conventional method of coupling prepolymers.

In future studies, we will try to apply the examined strategy to the preparation of multiblock copolymers which contain hydrogen-bonding segments in order to synthesize biologically inspired polymers with special mechanical properties.

\section{Acknowledgements}

Financial support by the Deutsche Forschungsgemeinschaft (DFG) for the project VA226/5-1 is gratefully acknowledged. P.V. acknowledges receipt of a Heisenberg-Professorship (DFG).

\section{References}

1. Nagata, Y.; Masuda, J.; Noro, A.; Cho, D.; Takano, A.; Matsushita, Y. Preparation and characterization of a styrene-isoprene undecablock copolymer and its hierarchical microdomain structure in bulk. Macromolecules 2005, 38, 10220-10225.

2. Sommerdijk, N.A.J.M.; Holder, S.J.; Hiorns, R.C.; Jones, R.G.; Nolte, R.J.M. Self-assembled structures from an amphiphilic multiblock copolymer containing rigid semiconductor segments. Macromolecules 2000, 33, 8289-8294.

3. Huh, K.M.; Bae, Y.H. Synthesis and characterization of poly(ethylene glycol)/poly(L-lactic acid) alternating multiblock copolymers. Polymer 1999, 40, 6147-6155.

4. Lee, D.; Lee, S.H.; Kim, S.; Char, K.; Park, J.H.; Bae, Y.H. Micro-phase-separation behavior of amphiphilic polyurethanes involving poly(ethylene oxide) and poly(tetramethylene oxide). J. Polym. Sci. B Polym. Phys. 2003, 41, 2365-2374.

5. Gersappe, D.; Harm, P.K.; Irvine, D.; Balazs, A.C. Contrasting the compatibilizing activity of comb and linear copolymers. Macromolecules 1994, 27, 720-724.

6. Leclerc, E.; Daoud, M. Multiblock copolymers at interfaces: concentration and selectivity effects. Macromolecules 1997, 30, 293-300.

7. Eastwood, E.A.; Dadmun, M.D. Multiblock copolymers in the compatibilization of polystyrene and poly(methyl methacrylate) blends: Role of polymer architecture. Macromolecules 2002, 35, 5069-5077.

8. Eastwood, E.; Viswanathan, S.; O’Brien, C.P.; Kumar, D.; Dadmun, M.D. Methods to improve the properties of polymer mixtures: Optimizing intermolecular interactions and compatibilization. Polymer 2005, 46, 3957-3970.

9. He, C.; Kim, S.W.; Lee, D.S. In situ gelling stimuli-sensitive block copolymer hydrogels for drug delivery. J. Control. Release 2008, 127, 189-207.

10. Yu, L.; Ding, J. Injectable hydrogels as unique biomedical materials. Chem. Soc. Rev. 2008, 37, 1473-1481.

11. Rodriguez-Hernandez, J.; Checot, F.; Gnanou, Y.; Lecommandoux, S. Toward 'smart' nano-objects by self-assembly of block copolymers in solution. Progr. Polym. Sci. 2005, 30, 691-724.

12. Löwik, D.W.P.M.; Ayres, L.; Smeenk, J.M.; Van Hest, J.C.M. Synthesis of bio-inspired hybrid polymers using peptide synthesis and protein engineering. Adv. Polym. Sci. 2006, 202, 19-52. 
13. Gaymans, R.J. Segmented copolymers with monodisperse crystallizable hard segments: Novel semi-crystalline materials. Progr. Polym. Sci. 2010, in press.

14. Schwabe, M.; Rotzoll, R.; Kuechemann, S.; Nadimpalli, K.; Vana, P.; Samwer, K. Relaxation processes of poly(tert-butyl acrylate) chemically confined via hydrogen bonds. Macromol. Chem. Phys. 2010, 211, 1673-1677.

15. Biemond, G.J.E.; Feijen, J.; Gaymans, R.J. Segmented block copolymers with monodisperse hard segments: The influence of H-bonding on various properties. Macromol. Mater. Eng. 2009, 294, 492-501.

16. Matsushita, Y.; Mogi, Y.; Mukai, H.; Watanabe, J.; Noda, I. Preparation and morphology of multiblock copolymers of the (AB $)_{n}$ type. Polymer 1994, 35, 246-249.

17. Spontak, R.J.; Smith, S.D. Perfectly-alternating linear $(\mathrm{AB})_{n}$ multiblock copolymers: Effect of molecular design on morphology and properties. J. Polym. Sci. B Polym. Phys. 2001, 39, 947-955.

18. Chiefari, J.; Chong, Y.K.B.; Ercole, F.; Krstina, J.; Jeffery, J.; Le, T.P.T.; Mayadunne, R.T.A.; Meijs, G.F.; Moad, C.L.; Moad, G. et al. Living free-radical polymerization by Reversible Addition-Fragmentation chain Transfer: The RAFT process. Macromolecules 1998, 31, 5559-5562.

19. Moad, G.; Rizzardo, E.; Thang, S.H. Living radical polymerization by the RAFT process. Aust. J. Chem. 2005, 58, 379-410.

20. Arita, T.; Beuermann, S.; Buback, M.; Vana, P. RAFT polymerization of methyl acrylate in carbon dioxide. Macromol. React. Eng. 2005, 290, 283-293.

21. Arita, T.; Buback, M.; Janssen, O.; Vana, P. RAFT-polymerization of styrene up to high pressure: Rate enhancement and improved control. Macromol. Rapid Commun. 2004, 25, 1376-1381.

22. Nguyen, D.H.; Wood, M.R.; Zhao, Y.; Perrier, S.; Vana, P. Solid-supported MADIX polymerization of vinyl acetate. Macromolecules 2008, 41, 7071-7078.

23. Boyer, C.; Stenzel, M.H.; Davis, T.P. Building nanostructures using RAFT polymerization. J. Polym. Sci. A Polym. Chem. 2011, 49, 551-595.

24. Vana, P. Kinetic aspects of RAFT polymerization. Macromol. Symp. 2007, 248, 71-81.

25. Krstina, J.; Moad, G.; Rizzardo, E.; Winzor, C.L.; Berge, C.T.; Fryd, M. Narrow polydispersity block copolymers by free-radical polymerization in the presence of macromonomers. Macromolecules 1995, 28, 5381-5385.

26. Hadjiantoniou, N.A.; Krasia-Christoforou, T.; Loizou, E.; Porcar, L.; Patrickios, C.S. Alternating amphiphilic multiblock copolymers: Controlled synthesis via RAFT polymerization and aqueous solution characterization. Macromolecules 2010, 43, 2713-2720.

27. Mayadunne, R.T.A.; Rizzardo, E.; Chiefari, J.; Krstina, J.; Moad, G.; Postma, A.; Thang, S.H. Living polymers by the use of trithiocarbonates as Reversible Addition-Fragmentation chain Transfer (RAFT) agents: ABA triblock copolymers by radical polymerization in two steps. Macromolecules 2000, 33, 243-245.

28. You, Y.Z.; Hong, C.Y.; Pan, C.Y. A novel strategy for synthesis of multiblock copolymers. Chem. Commun. 2002, 25, 2800-2801.

29. Motokucho, S.; Sudo, A.; Sanda, F.; Endo, T. Controlled monomer insertion into polymer main chain: Synthesis of sequence ordered polystyrene containing thiourethane and trithiocarbonate units by the RAFT process. Chem. Commun. 2002, 17, 1946-1947. 
30. Motokucho, S.; Sudo, A.; Endo, T. Polymer having a trithiocarbonate moiety in the main chain: Application to Reversible Addition-Fragmentation chain Transfer controlled thermal and photoinduced monomer insertion polymerizations. J. Polym. Sci. A Polym. Chem. 2006, 44, 6324-6331.

31. Zhou, Y.; Jiang, K.; Song, Q.; Liu, S. Thermo-induced formation of unimolecular and multimolecular micelles from novel double hydrophilic multiblock copolymers of $N, N$-dimethylacrylamide and $N$-isopropylacrylamide. Langmuir 2007, 23, 13076-13084.

32. Liu, Y.; Cavicchi, K.A. Reversible Addition Fragmentation chain Transfer (RAFT) polymerization with a polymeric RAFT agent containing multiple trithiocarbonate groups. Macromol. Chem. Phys. 2009, 210, 1647-1653.

33. Hu, J.; Ge, Z.; Zhou, Y.; Zhang, Y.; Liu, S. Unique thermo-induced sequential gel-sol-gel transition of responsive multiblock copolymer-based hydrogels. Macromolecules 2010, 43, 5184-5187.

34. Hong, J.; Wang, Q.; Fan, Z. Synthesis of multiblock polymer containing narrow polydispersity blocks. Macromol. Rapid Commun. 2006, 27, 57-62.

35. Zhang, L.; Wang, Q.; Lei, P.; Wang, X.; Wang, C.; Cai, L. Multiblock poly(4-vinylpyridine) and its copolymer prepared with cyclic trithiocarbonate as a Reversible Addition-Fragmentation Transfer agent. J. Polym. Sci. A Polym. Chem. 2007, 45, 2617-2623.

36. Bussels, R.; Bergman-Göttgens, C.; Meuldijk, J.; Koning, C. Multiblock copolymers synthesized in aqueous dispersions using multifunctional RAFT agents. Polymer 2005, 46, 8546-8554.

37. Ebeling, B.; Eggers, M.; Vana, P. Ideal molecular weight distributions of multiblock copolymers prepared via RAFT polymerization. Macromolecules 2010, 43, 10283-10290.

38. Beuermann, S.; Paquet, D.A.; McMinn, J.H.; Hutchinson, R.A. Determination of free-radical propagation rate coefficients of butyl, 2-ethylhexyl, and dodecyl acrylates by pulsed-laser polymerization. Macromolecules 1996, 29, 4206-4215.

39. Aoyagi, N.; Ochiai, B.; Mori, H.; Endo, T. Mild and efficient one-step synthesis of trithiocarbonates using minimum amount of $\mathrm{CS}_{2}$. Synlett 2006, 4, 636-638.

40. You, Y.Z.; Hong, C.Y.; Pan, C.Y. A new strategy for the synthesis of polytrithiocarbonates using a polymeric support system. Macromol. Rapid Commun. 2002, 23, 776-780.

41. Buback, M.; Junkers, T.; Vana, P. Laser single pulse initiated RAFT polymerization for assessing chain-length dependent radical termination kinetics. Macromol. Rapid Commun. 2005, 26, 796-802.

42. Qiu, X.P.; Winnik, F.M. Facile and efficient one-pot transformation of RAFT polymer end groups via a mild aminolysis/michael addition sequence. Macromol. Rapid Commun. 2006, 27, 1648-1653.

43. Aoyagi, N.; Endo, T. Functional RAFT agents for radical-controlled polymerization: Quantitative synthesis of trithiocarbonates containing functional groups as RAFT agents using equivalent amount of $\mathrm{CS}_{2}$. J. Polym. Sci. A Polym. Chem. 2009, 47, 3702-3709.

44. Boschmann, D.; Vana, P. Z-RAFT star polymerizations of acrylates: Star coupling via intermolecular chain transfer to polymer. Macromolecules 2007, 40, 2683-2693.

45. Boyer, C.; Bulmus, V.; Davis, T.P. Efficient usage of thiocarbonates for both the production and the biofunctionalization of polymers. Macromol. Rapid Commun. 2009, 30, 493-497. 
46. Lima, V.; Jiang, X.; Brokken-Zijp, J.; Schoenmakers, P.J.; Klumperman, B.; Linde, R.V.D. Synthesis and characterization of telechelic polymethacrylates via RAFT polymerization. J. Polym. Sci. A Polym. Chem. 2005, 43, 959-973.

47. Boyer, C.; Granville, A.; Davis, T.P.; Bulmus, V. Modification of RAFT-polymers via thiol-ene reactions: A general route to functional polymers and new architectures. J. Polym. Sci. A Polym. Chem. 2009, 47, 3773-3794.

48. Xu, J.; He, J.; Fan, D.; Wang, X.; Yang, Y. Aminolysis of polymers with thiocarbonylthio termini prepared by RAFT polymerization: The difference between polystyrene and polymethacrylates. Macromolecules 2006, 39, 8616-8624.

49. Peyser, P. Glass transition temperatures of polymers. In Polymer Handbook, 3rd ed.; Brandrup, J., Immergut, E.H., Eds.; Wiley-Interscience: New York, NY, USA, 1989; pp. 209-277.

(c) 2011 by the authors; licensee MDPI, Basel, Switzerland. This article is an open access article distributed under the terms and conditions of the Creative Commons Attribution license (http://creativecommons.org/licenses/by/3.0/.) 